\title{
To Share or Not to Share: Assessing Knowledge Sharing, Interemployee Helping, and Their Antecedents Among Online Knowledge Workers
}

\author{
Chieh-Peng Lin · Sheng-Wuu Joe
}

Received: 29 March 2011/Accepted: 8 August 2011/Published online: 10 November 2011

(C) Springer Science+Business Media B.V. 2011

\begin{abstract}
Sharing and helping are important issues in ethical research. This study proposes a model based on flow theory by postulating key antecedents as the critical drivers of knowledge sharing and interemployee helping. Flow is the holistic sensation that employees feel when they act with total immersion and engagement, facilitating individuals' reciprocal activities such as knowledge sharing and interemployee helping. In the proposed model, knowledge sharing is influenced by flow experience directly and also indirectly via the mediation of interemployee helping. Accordingly, the flow experience is influenced simultaneously by four exogenous factors related to individuals' perception about their work: work skills, selffulfillment in challenges, perceived control, and vividness. This study contributes to the knowledge management literature by extending flow theory to the area of knowledge sharing and interemployee helping, by validating idiosyncratic antecedent drivers of the flow theory, and by performing a practical operationalization of the flow experience. This research also provides managerial implications for business leaders to boost their employees' ethical behavior in terms of sharing and helping.
\end{abstract}

Keywords Knowledge sharing - Interemployee helping · Flow experience

C.-P. Lin $(\bowtie)$

Institute of Business \& Management, National Chiao Tung

University, Hsinchu, Taiwan

e-mail: jacques@mail.nctu.edu.tw

S.-W. Joe

Department of Business Administration, Vanung University, Chung-Li, Taiwan

\section{Introduction}

Knowledge sharing and interemployee helping are important ethical issues to organizations because organizational competitive position and effectiveness can be substantially undermined due to the lack of such sharing and helping (Lin and Chang 2008; Lin 2006). Whereas knowledge sharing enables the sharing of relevant experiences and information between organizational members, interemployee helping allows individuals to complement one another with mutual assistance in operations (Siemsen et al. 2007). Previous research has connected knowledge sharing and interemployee helping to a variety of factors such as organizational culture, transient situation-specific attitudes, and incentives (e.g., Mooradian et al. 2006). However, no previous research has connected knowledge sharing or interemployee helping to a personal experiential state characterized by intense focus (i.e., flow). Our goal is to understand the reasons why people are willing to help others and share their knowledge professionally via flow.

Flow is the mental state of operation in which an individual is fully immersed in what he or she is doing by a psychological feeling of energized focus, full involvement, and success in the process of the activity, facilitating individuals' reciprocal activities (Csikszentmihalyi 1990) such as knowledge sharing and interemployee helping. Previous literature has overemphasized the tangible incentives that induce helping and knowledge sharing in workgroups by assuming that employees share their knowledge and help others to gain rewards (e.g., Siemsen et al. 2007). In fact, financial bonuses may result in increased use of technologies of knowledge sharing or interpersonal helping, but they are unlikely to increase such sharing and helping themselves (Hendriks 1999; Hwang 2008). For that reason, this study examining knowledge sharing and interemployee 
helping based on the flow theory complements previous literature, since self-motivated and discretionary perception (e.g., flow) that facilitate such sharing and helping are seldom considered in the literature (e.g., Liao 2006).

Flow is the holistic sensation that employees feel when they act with total immersion and engagement, when nothing else seems to matter at the time (Csikszentmihalyi 1990; Eisenberger et al. 2005). The state of flow occurs when employees participate in a work activity for their own sake, and the participative state is so satisfying that employees try to continue partaking in the activity (Choi et al. 2007). Csikszentmihalyi coined the term "flow" to refer to "optimal experience" events (Csikszentmihalyi 1975; Pearce and Howard 2004). Specifically, flow theory highlights the necessity of online members' experience reinforcement in boosting interemployee helping and knowledge sharing given that flow mechanisms encourage individuals to have a strong focus and concentration towards work activities that involve their participation and social interaction with others in depth. Unfortunately, little is known so far about how the flow theory can be appropriately utilized in research associated with online work contexts across business organizations.

Due to the absence of the aforementioned literature, this study derives two research questions of interest: (1) How can the flow theory be appropriately applied to research of working behavior in virtual working contexts? (2) What critical antecedents and mediators drive interemployee helping and knowledge sharing in virtual organizations and how are they accomplished? Exploring these research questions is important because an improved understanding of such helping and sharing can remind management to treat these determinants with great caution. Many previous studies examining the antecedents or mediators of knowledge sharing and helping focused on organizational factors such as organizational trust, culture, and financial incentives (Cabrera and Cabrera 2002), while others focused on task-related or interpersonal factors such as task interdependence, social network ties, etc. (e.g., Staples and Webster 2008; Lin 2006). Nevertheless, none of the previous studies attempted to explore the antecedents or mediators based on such a holistic and optimal experience as flow.

This study is different from previous work in two important ways. First, whereas the majority of prior research applies flow theory from a hedonic aspect such as online shopping, gaming, playing, learning, or friendmaking (e.g., Choi et al. 2007; Koufaris 2002; Mathwick and Rigdon 2004), vocational issues from a nonhedonic aspect are rarely examined in flow theory (e.g., required skills, task challenges, or job self-esteem). Flow does not just occur during relaxing moments or passive entertainment, but rather when people are actively involved in a task that stretches their mental and/or physical abilities (Williams and Dargel 2004). Traditional antecedents of flow experience, such as skills and challenges that are popularly used in the hedonic context (e.g., online games), are seldom applied in the online working context. This study is one of the first to utilize flow theory in evaluating individuals' flow experience of their vocational behavior and its antecedents in business organizations (e.g., Bakker 2005; Eisenberger et al. 2005). It is interesting for both researchers and practitioners to discover whether flow in hedonic settings can be analogized to flow in nonhedonic (or work) settings (e.g., Eisenberger et al. 2005).

Second, this study is also one of the few to assess online communication outcomes (i.e., interemployee helping and knowledge sharing) based on flow theory by empirically testing a model through a survey of online knowledge workers (e.g., Chen et al. 2008). Although many organizations unite their employees by encouraging them to share knowledge and help each other, little is known about whether the flow experience and its antecedents can truly contribute to knowledge sharing or interemployee helping in virtual work contexts, which have become popular in today's business organizations. Easterby-Smith et al. (2000) estimate that approximately $70 \%$ of research publications on knowledge management have focused on issues related to the Internet or information technology, suggesting the importance of virtual work contexts for knowledge sharing and interemployee helping (e.g., Easterby-Smith and Lyles 2003). For example, in a cooperative situation in which their is positive attraction for an online task (e.g., flow experience), people help each other accomplish a goal that is beneficial to both of them (Hsu et al. 2009), suggesting the potential relationship between flow experience and interemployee helping. Collectively, it is interesting for scholars and management to find out whether knowledge sharing and interemployee helping via flow can be obtained online rather than offline.

The rest of this paper is organized as follows. The "Theory and Research Model" section describes the theoretical underpinnings of the flow theory and formulates a research model of knowledge sharing based on this theory. The "Methods" section then presents the research methods used in the study, including the choice of empirical context, subject sample, and instrumentation. The "Results" section then describes the data analysis procedures and empirical results. The "Discussion" section outlines the implications and limitations of the findings of the study.

\section{Theory and Research Model}

Flow Theory

The study of flow has its roots in research on personal causation, self-actualization, and play (Quinn 2005). Flow 
experiences are described as states of intense concentration or absolute absorption in an activity (Csikszentmihalyi 1990). In organizational contexts, deep absorption in activities has been shown to promote optimal working experiences (i.e., flow experience). According to Csikszentmihalyi (1990), flow experiences are intrinsically rewarding, since they allow individuals to become fully involved in a task and stretch their skills and abilities to the limit. In addition to increasing intrinsic task interest, it is argued by Csikszentmihalyi that repeated experience of flow in a given context would have a pervasive incremental effect on positive outcomes (Csikszentmihalyi 1999). Hence, a job, learning, hobby, sports, or retail activity that repeatedly provided high but manageable challenges would come to have a major influence on positive outcomes such as performance, knowledge sharing, etc. (Eisenberger et al. 2005). A clear sign of flow is the merging of action and awareness, because flow describes the experience of having actions and awareness merge (Csikszentmihalyi 1990; Quinn 2005). The merging of action and awareness reflects the extent to which an activity becomes spontaneous (e.g., automatic and self-motivated), and individuals stop being aware of themselves as separate from the organizational activity they are performing (Csikszentmihalyi 1990). Based on the above rationale, individuals' flow experience in this study is defined as a holistic experience particularly in working organizations in which members are so focused that it amounts to absolute engagement in their job activities, causing a sense of discovery (Heckman 1997) and a strong feeling of motivation to reach improved levels of working actions.

Flow can be considered the experience of temporally merging individuals' situation awareness with the automatic application of activity-relevant knowledge and skills in, for example, online collaboration with their coworkers. Previous research suggests that some job tasks are more fun and inspirational than others, and more likely to lead to a feeling of flow (Amabile et al. 2003). It has been found that, for instance, people engage themselves in depth during web discussions so as to achieve reciprocity with other people (e.g., exchanging job tips) (Lee et al. 2006), implying the potential influence of flow experience on knowledge sharing and interemployee helping.

\section{Research Model and Hypotheses}

Based on the flow theory discussed above, this study proposes a model explaining the formation of knowledge sharing and interemployee helping based on flow theory. In the model, knowledge sharing is influenced by individuals' flow experience directly and also indirectly via the mediation of interemployee helping. Accordingly, the flow experience is influenced simultaneously by four exogenous factors related to organizational work: work skills, selffulfillment in challenges, perceived control, and perceived vividness.

Since flow theory is strongly associated with the concept of intrinsic motivation, managers in business organizations should ask how to create knowledge sharing that favors intrinsic motivation. At its most basic, flow is simply a description of employees enjoying themselves (Chan and Ahern 1999). Employees are in a state of enjoyment because they have situated themselves in an optimal working environment, implying that the goal of any knowledge sharing is to help others acquire the requisite knowledge or skill under optimal conditions (Chan and Ahern 1999). It has been convincingly argued that the learning (or knowledge sharing) process itself-and not just the result-should be interesting, if employees seek high intrinsic motivation (Rieber et al. 1998). "Hard fun" or "serious play" are intense knowledge sharing situations where employees engage lots of time and energy and that offer equally intensive pleasure at certain moments and which have been recognized as "flow" or "optimal experience" (Csikszentmihalyi 1990; Rieber et al. 1998).

When employees enjoy executing their work and their subjective experience of time is altered (i.e., strong flow experience), they attempt to stretch their capabilities and thus increase the likelihood that they will, for example, share updated information and help each other, suggesting the positive influence of flow experience on interemployee helping and knowledge sharing. Flow experience represents individuals' full engagement, and their synergy manifests in the ways in which they accomplish high levels of organizational solidarity that leads to great interemployee helping and knowledge sharing. Thus, the first two hypotheses are derived as follows.

H1 Flow experience has a positive effect on knowledge sharing among online knowledge workers.

H2 Flow experience has a positive effect on interemployee helping among online knowledge workers.

Interemployee helping is derived from the concept of altruism (Organ 1988), which encompasses discretionary behaviors that assist others with relevant tasks or problems in the organization. Previous literature has indicated that interemployee helping and knowledge sharing are correlated (Siemsen et al. 2007). Individuals who are engaged in intellectual pursuits and enjoy helping others are intrinsically motivated to share their knowledge with others (Wasko and Faraj 2000, 2005). Employees' dedication to helping others is important for knowledge sharing since this helping process facilitates intangible knowledge collection and donation. Previous research has provided examples of people who are willing to help others by 
sharing their knowledge within a network of professionals (Mergel et al. 2008), implying the positive relationship between interemployee helping and knowledge sharing. Hence, working professionals, and particularly online knowledge workers, who enjoy helping one another are more likely to share knowledge with others (e.g., Lin 2007a), suggesting the hypothesis stated below.

H3 Interemployee helping has a positive effect on knowledge sharing among online knowledge workers.

Work skills represent employees' own judgment of their capabilities in performing their work. Different levels of perceived skills are associated with optimized mental states (e.g., immersion or concentration) and increased activation (Delespaul et al. 2004), suggesting the substantial influence of work skills on flow experience. According to flow theory, an activity is emotionally rewarding in relation to whether individuals believe that they have the skills to accomplish it (Schweinle et al. 2006). For example, if an employee rated his skill in the working organization (e.g., online marketing) as higher than the average skill experienced in all their daily activities (e.g., cooking, reading, cleaning his house), he would be predicted to experience flow at work (Eisenberger et al. 2005). As the level of individuals' skills has been identified as one of the most important antecedents to flow experience in some previous studies (Csikszentmihalyi 1990; Koufaris 2002), the following hypothesis in a virtual work context is likewise developed.

H4 Work skills have a positive effect on flow experience among online knowledge workers.

Self-fulfillment in challenges is considered the perceived degree of individuals' success in dealing with challenges when performing their work. Various ratios of work challenges are predicted to be associated with different qualities of flow experience (Schweinle et al. 2006). Previous research indicates that adequate challenges (e.g., accomplishable challenges) positively influence employees' response to the flow experience (Hoffman and Novak 1996) due to self-fulfillment perceived in the process of overcoming challenges. Working via interactions with others is often more challenging and inspiring than working individually, and thus employees experiencing strong self-fulfillment in challenges likely reach a higher level of flow experience. Consequently, the hypothesis can be stated as follows.

H5 Self-fulfillment in challenges has a positive effect on flow experience among online knowledge workers.

Perceived control can be defined as the level of individuals' control over their own actions and the environment in which they interact with others (Koufaris 2002). In other words, it considers feeling unrestricted or free to act in a variety of ways in a specific work situation (Mehrabian and Russel 1974). Even though perceived control has been similarly used across some theoretical models under slight variations with analogous construct names such as locus of control (Rotter 1996), self-efficacy, (Bandura 1982), and perceived behavioral control (Ajze 1991), these constructs have seldom been used in online vocational research. Virtual organizations and their working process that are totally out of control can be very discouraging to online members, and thus they are unlikely to concentrate on work activities, leading to weak flow experience. This phenomenon has been partially supported by previous research that studied perceived control as a factor influencing flow experience (e.g., Ghani and Deshpande 1994). Collectively, the hypothesis is derived and stated as follows.

H6 Perceived control has a positive effect on flow experience among online knowledge workers.

Perceived vividness is defined as the intrinsic enjoyment that employees perceive during their interaction with others in an organization (e.g., Hoffman and Novak 1996), similar to the emotional response of pleasure from environmental psychology (Koufaris 2002). Employees are unlikely to be stimulated to experience great flow if their work is often unpleasant and reveals inanition during organizational activities. By contrary, previous research indicates that individuals such as musicians, writers, painters, rock climbers, and sportsmen are found to enjoy a particular activity process itself and consequently become totally absorbed in the process (Csikszentmihalyi 1975), implying the following positive relationship between perceived vividness and flow experience.

H7 Perceived vividness has a positive effect on flow experience among online knowledge workers.

\section{Methods}

\section{Subjects}

The subjects surveyed in this study consist of online knowledge workers in Taiwan's high-technology industry. Note that knowledge workers are defined as individuals with the motivation and capacity to create new insights and to communicate, coach, and facilitate the implementation of new ideas (Horwitz et al. 2003, 2006), whereas the traditional worker has low skills/knowledge and a low preference for challenging work (Guest 2004). In previous literature, it appears that what really engages knowledge workers is work that is challenging (i.e., a typical flow), distinguishing knowledge workers from traditional workers 
in terms of flow theory (Quinn 2005). In the high-technology firms we surveyed, online workers can be considered online knowledge workers because they are mostly highly educated and deal with challenging tasks in their daily life. Based on individual-level analyses, virtual organizational or team members in information technology (IT) firms were recruited in this study, because virtual operations have become a very important work mode in modern industries nowadays. Using employees with virtual work experience helps improve the external validity of online knowledge sharing. Virtual working styles are the ways people use online technologies such as e-mail, chat tools, online conferencing, and instant messaging for virtual collaboration and work. Note that "online or virtual workers" refers to workers that rely heavily on online technologies to accomplish their work.

Fifty large IT firms located in the northern part of Taiwan from Taiwan's business directory were initially consulted, 17 of which consented to help us with the questionnaire investigation. Staff from the personnel department of the 17 firms helped distribute the questionnaires and collect it back in after 2 weeks. The respondents were invited to fill out the questionnaires in office hours whenever they felt available. The questionnaire also clearly assured that data collected from them would only be used in aggregated form for statistical analyses and any information relating to individual privacy would be kept confidential under all circumstances. Note that the firms sampled herein cannot be randomly chosen, since they must have an organized virtual working environment to meet the basic needs of our investigation. Nevertheless, the sampled firms that confirmed to us their utilization of virtual working styles reveal the fact that they are appropriate representative samples.

Of the 510 questionnaires provided to the subjects, 426 usable questionnaires were collected after follow-up by telephone (response rate 83.53\%), from 214 males $(50.23 \%)$ and 212 females (49.77\%). In the sample, 395 employees were between 20 and 40 years old (92.93\%), while the other 31 employees were 40 years old or above (7.07\%). The sample included 396 employees with bachelor degree or above $(92.96 \%)$ and 30 employees with high-school degree or under $(7.04 \%)$. It also revealed that 383 employees $(89.91 \%)$ had job experience using the Internet for 1 year or more. These characteristics show that the sample firms were appropriate representatives of the population of virtual knowledge workers in high-technology industries.

\section{Measures}

In this study, constructs were measured using five-point Likert scale items drawn from the existing literature and then modified repeatedly by a focus group of five people, including three graduate students and two professors familiar with human resource management and organizational behavior. The measurements were thoroughly verified via two pilot tests before the actual survey. The pilot test data were subjected to exploratory factor analysis (EFA) and reliability analysis to identify items that loaded poorly on their hypothesized scales, which were then further refined. The questionnaires in Chinese and English were both examined and compared based on tips proposed by Reynolds et al. (1993). A high degree of correspondence between the two questionnaires (Chinese versus English) assures that the language translation process did not introduce substantial artificial translation biases. The scale items modified from the existing literature cover traits or features associated with virtual work modes of business organizations.

It is important to note that, although concentrating and focusing are components of an experience of flow (Csikszentmihalyi 1990), flow experience only occurs when individuals perceive a distorted sense of time. Thus, the perceived flow experience in this study is measured as individuals' mental flow experience based on the holistic effects of both their perceived concentration and sense of time (e.g., experiencing immersion in, frequently paying attention to, and spending most time in online collaboration with coworkers). These features are highly consistent with those proposed by Csikszentmihalyi (1990) (e.g., concentration, absorption, loss of the feeling of self-consciousness, etc.), supporting the appropriateness of our measurement items in this study. Since not all the features are needed for flow to be experienced (Csikszentmihalyi and Rathunde 1993), our measurement of critical features herein for the detection of individuals' flow experience is effective. A commonly used technique to measure flow experience is to survey participants, after an activity, to obtain Likert scale ratings for the affective measures of immersion, involvement, and enjoyment (Webster et al. 1993; Ghani 1991). From these measures, a score can be reasonably derived and represents the overall degree of flow for the duration of the activity (Pearce and Howard 2004), supporting the use of this technique, which is also used for measuring our flow experience. The Appendix lists all the scale items and their original sources.

\section{Results}

Data Analysis

The survey data were analyzed using a two-step structural equation modeling (SEM) approach consisting of measurement and structural model testing (Anderson and 
Gerbing 1998). Empirical results from each stage of analysis are presented in the following.

\section{Measurement Model}

In measurement model testing, the overall goodness-of-fit indices shown in Table 1 indicate that all the fits of the measurement model are satisfactory. Particularly, the model's normalized chi-square (chi-square/degrees of freedom) was smaller than the recommended value of 3.0. The adjusted goodness-of-fit index (AGFI), the comparative fit index (CFI), the goodness-of-fit index (GFI), the nonnormed fit index (NNFI), and the normed fit index (NFI) all exceeded 0.90, while the root-mean-square residual (RMR) was smaller than 0.05 and the root-mean-square error of approximation (RMSEA) was smaller than 0.08 (Bentler and Bonett 1980). These values obviously suggest that the model hypothesized in this study fits well with the empirical data collected from industries.

Convergent validity was identified by examining the following three conditions (Fornell and Larcker 1981). To begin with, all factor loadings were statistically significant at $P<0.001$, as presented in Table 1 . The average variance extracted (AVE) for all research constructs equaled or exceeded 0.50 , implying that the overall proposed scale items capture sufficient variance in their underlying construct compared with that attributable to the measurement error. Finally, the reliabilities for each construct exceeding 0.70 meet the general requirement of reliability for research instruments. Consequently, the empirical data in this study assure convergent validity.

This study applies chi-square difference tests to evaluate discriminant validity, because this has the advantage of simultaneous pairwise comparisons for the constructs based on the Bonferroni method. Controlling for the experiment-wise error rate at overall significance level of 0.01 , the Bonferroni method indicates that the critical value of the chi-square difference should be 12.21. In this study, chi-square difference statistics for all pairs of constructs exceeded the critical value of 12.21 (Table 2), thereby assuring quality discriminant validity in this study.

\section{Structural Model}

The measurement model in the preceding section was then transformed to a structural model that reflects the model paths hypothesized in our research framework for the purpose of statistical testing for the paths. Given that individuals' tenure might potentially affect the strength of their knowledge sharing, we included tenure as a control variable herein. Figure 1 presents the empirical results of this statistical analysis, which shows that six out of the seven hypothesized model paths of this study were validated at the $P<0.01$ significance level.
Flow experience has significant effects on both knowledge sharing and interemployee helping with standardized path coefficients of 0.32 and 0.58 , respectively $(\mathrm{H} 1$ and $\mathrm{H} 2$ are supported). Knowledge sharing is significantly influenced by interemployee helping with standardized path coefficient of 0.48 (H3 is supported). Flow experience is significantly influenced by work skills, perceived control, and perceived vividness with standardized path coefficients of $0.18,0.27$, and 0.55 , respectively ( $\mathrm{H} 4, \mathrm{H} 6$, and $\mathrm{H} 7$ are supported), but is insignificantly affected by self-fulfillment in challenges (H5 is not supported).

The lack of support for H5 is surprising and may have occurred because some excessive challenges that cause psychological stress and sufferings could hardly be restored in a short period of time (e.g., Carmeli 2005; Spencer and Steers 1980), leading to the insignificant influence of selffulfillment in challenges on flow experience. Nevertheless, this unexpected empirical result of the unsupported hypothesis may warrant future research so that the real causes of this insignificant relationship between self-fulfillment in challenges and flow experience can be accurately interpreted.

\section{Discussion}

This study provides strong evidence for the application of flow theory in studying knowledge sharing and interemployee helping in depth. The major results of the empirical tests in this study confirm that interemployee helping and knowledge sharing are both affected indirectly by work skills, perceived control, and perceived vividness through the full mediation of flow experience, whereas knowledge sharing is also affected by interemployee helping. While previous research suggests that the quality of subjective experience is a theoretical function of two subjective variables, including perceived challenges and perceived skills (Massimini et al. 1987), the results of empirical tests in this study advance the previous research by containing more comprehensive variables (i.e., four antecedents). In other words, complementing previous research, our findings suggest that work skills, perceived control, and perceived vividness have joint ability to increase employees' task interest and elevate their concentration (i.e., states of flow), consequently boosting interemployee helping and knowledge sharing.

\section{Theoretical and Methodological Implications}

The theoretical implications of this study include two critical points. First, given the increased interactive nature of online activities (or communities) in today's business organizations, it is important to incorporate the notion of 
Table 1 Standardized loadings and reliabilities
Goodness-of-fit indices

$(N=426): \chi_{188}^{2}=303.34$

$(P$ value $<0.001)$

$\mathrm{NNFI}=0.97 ; \mathrm{NFI}=0.94$;

$\mathrm{CFI}=0.98$; $\mathrm{GFI}=0.94$;

AGFI $=0.92 ;$ RMR $=0.02$;

RMSEA $=0.04$

\begin{tabular}{|c|c|c|c|c|}
\hline Construct & Indicators & Standardized loading & AVE & Cronbach's $\alpha$ \\
\hline \multirow[t]{3}{*}{ Knowledge sharing } & KS1 & $0.81(t=18.89)$ & \multirow[t]{3}{*}{0.64} & \multirow[t]{3}{*}{0.84} \\
\hline & KS2 & $0.80(t=18.69)$ & & \\
\hline & KS3 & $0.79(t=18.24)$ & & \\
\hline \multirow[t]{4}{*}{ Interemployee helping } & $\mathrm{IH} 1$ & $0.85(t=20.89)$ & \multirow[t]{4}{*}{0.66} & \multirow[t]{4}{*}{0.88} \\
\hline & $\mathrm{IH} 2$ & $0.81(t=19.48)$ & & \\
\hline & $\mathrm{IH} 3$ & $0.85(t=21.02)$ & & \\
\hline & $\mathrm{IH} 4$ & $0.73(t=16.82)$ & & \\
\hline \multirow[t]{3}{*}{ Flow experience } & TF1 & $0.83(t=19.89)$ & \multirow[t]{3}{*}{0.67} & \multirow[t]{3}{*}{0.86} \\
\hline & $\mathrm{TF} 2$ & $0.85(t=20.76)$ & & \\
\hline & TF3 & $0.78(t=18.25)$ & & \\
\hline \multirow[t]{3}{*}{ Work skills } & SK1 & $0.78(t=17.28)$ & \multirow[t]{3}{*}{0.61} & \multirow[t]{3}{*}{0.82} \\
\hline & SK2 & $0.83(t=18.71)$ & & \\
\hline & SK3 & $0.72(t=15.79)$ & & \\
\hline \multirow[t]{3}{*}{ Self-fulfillment in challenges } & $\mathrm{CH} 1$ & $0.75(t=15.91)$ & \multirow[t]{3}{*}{0.50} & \multirow[t]{3}{*}{0.76} \\
\hline & $\mathrm{CH} 2$ & $0.69(t=14.39)$ & & \\
\hline & $\mathrm{CH} 3$ & $0.69(t=14.49)$ & & \\
\hline \multirow[t]{3}{*}{ Perceived control } & $\mathrm{CO} 1$ & $0.76(t=16.57)$ & \multirow[t]{3}{*}{0.50} & \multirow[t]{3}{*}{0.74} \\
\hline & $\mathrm{CO} 2$ & $0.67(t=14.30)$ & & \\
\hline & $\mathrm{CO} 3$ & $0.68(t=14.35)$ & & \\
\hline \multirow[t]{3}{*}{ Perceived vividness } & VI1 & $0.88(t=22.45)$ & \multirow[t]{3}{*}{0.75} & \multirow[t]{3}{*}{0.90} \\
\hline & VI2 & $0.87(t=21.82)$ & & \\
\hline & VI3 & $0.85(t=21.31)$ & & \\
\hline
\end{tabular}

flow into existing models of knowledge sharing and interemployee helping to enhance current understanding of sharing and helping in virtual business organization settings. Indeed, flow is important not only for understanding the use of interactive IT such as online video games (e.g., gamer immersion), but also for many business application in a virtual world such as online knowledge sharing, online trouble shooting, etc. Second, the test of the flow theory and hypotheses conducted in this study was stronger than that of prior studies on knowledge sharing (or other job outcomes) as this study controlled for the effects of perceived control and perceived vividness as independent variables. As a result, this study clarifies the nomological associations between flow and various salient antecedents, ultimately driving knowledge sharing and interemployee helping.

From the methodological point of view, this study provides a contribution to flow theory by further refining scale items (e.g., perceived vividness) from previous literature, since none of the existing scale items related to flow theory can be directly used in work contexts without modification. Nevertheless, the empirical results of this research should be interpreted and applied in light of its limitations. The first limitation is associated with the cross-sectional nature of the survey used in this study, which limits our ability to obtain causal inferences; that is to say, a cross-sectional design with individual-level analysis may not be the best design to capture flow as an antecedent of knowledge sharing and interemployee helping. Hence, longitudinal research based on experimental designs complementary to this study may be conducted, because such experimental designs help researchers include a control group that is not exposed to flow. The second limitation of this study is the possibility of common method bias given the usage of Likert scales. To further clarify this issue, a Harman's single factor test (Podsakoff and Organ 1986) was performed. An exploratory factor analysis of all items for the seven constructs in Table 2 reveals seven factors explaining $18.85 \%, 14.40 \%, 14.16 \%, 13.69 \%, 13.55 \%, 12.85 \%$, and $12.50 \%$ of the total variance, respectively. These values reveal that the variances are appropriately distributed among the proposed constructs and none of the factors can account for a majority of the total variance in the analysis, revealing that common method bias is not a threat in this study. The third limitation of this study is related to the sample of professionals in Taiwan, thus the generalizability of this study to other national cultures and industries may be limited.

\section{Managerial Implications}

The significant influence of interemployee helping on knowledge sharing reveals that the first priority for management is to create an altruistic environment in which 
Table 2 Chi-square difference tests for examining discriminant validity
Significant at the 0.001 overall significance level by using the Bonferroni method
Construct pair

$\chi_{188}^{2}=303.34$ (unconstrained model)

(Knowledge sharing, interemployee helping) $\chi_{189}^{2}($ constrained model $) \quad \chi^{2}$ difference

(Knowledge sharing, flow experience)

$552.04 * * *$

248.70

(Knowledge sharing, work skills)

(Knowledge sharing, self-fulfillment in challenges)

(Knowledge sharing, perceived control)

(Knowledge sharing, perceived vividness)

$637.01 * * *$

333.67

$634.32 * * *$

330.98

$487.63 * * *$

184.29

$441.92 * * *$

138.58

$626.66 * * *$

323.32

$712.55 * * *$

409.21

$687.04 * * *$

383.70

(Interemployee helping, work skills)

$533.26 * * *$

229.92

$477.11 * * *$

173.77

$816.72 * * *$

513.38

$591.22 * * *$

287.88

(Flow experience, work skills)

$517.01 * * *$

213.67

(Flow experience, perceived control)

$422.23 * * *$

118.89

(Flow experience, perceived vividness)

$486.77 * * *$

183.43

(Work skills, self-fulfillment in challenges)

(Work skills, perceived control)

$537.99 * * *$

234.65

$509.65 * * *$

206.31

$632.79 * * *$

329.45

(Self-fulfillment in challenges, perceived control)

$401.79 * * *$

98.45

(Self-fulfillment in challenges, perceived vividness)

$489.75^{* * *}$

186.41

(Perceived control, perceived vividness)

$409.77 * * *$

106.43

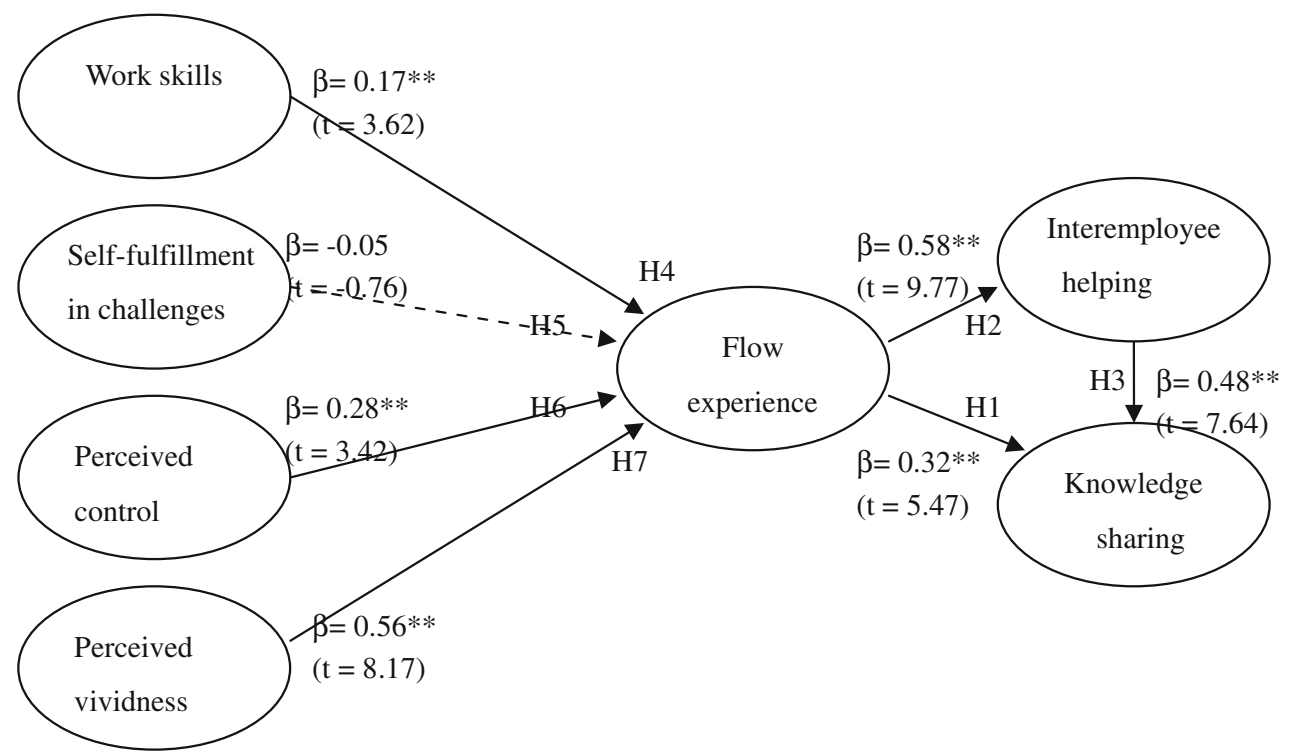

Fig. 1 Research framework. **Significant at the 0.01 overall significance level. Note Tenure is included as a control variable and reveals its insignificance $(t=0.56)$

people care about and help each other before knowledge sharing can be efficiently realized. Given that knowledge is so precious in today's world, online members may be unwilling to share their knowledge (i.e., precious intellectual capital) if they have no intention to help others in the first place. Although this work stresses findings based on virtual work contexts, it does not suggest the unimportance of nonvirtual work modes. Previous research presents that, depending on the community type and situation, both online and offline interaction channels may be used for 
efficient knowledge sharing (Erat et al. 2006). For instance, software engineers organized face-to-face (offline) departmental meetings where each member could present the way they were treating clients and discuss difficulties with the implementation of research and development (R\&D) plans. They also searched for other departments (e.g., in various locations) that were working on a same project or similar issues and organized online organizational activities to link the departments to one another. Examples of such activities were typically joint online and offline meetings, which is becoming increasingly popular in modern industries.

Flow experience as the only mediator in influencing knowledge sharing and interemployee helping in this study leads to an important insight for management learning literature. The mediating role of flow experience seems to suggest "the reasonable man adapts himself to the world." According to flow theory, self disappears from awareness during flow (Kiili and Lainema 2008). The best way for an individual to obtain successful knowledge sharing (or interemployee helping) is to stop thinking about what others should share with (or how they should help) him. Instead, an individual should take the immersed initiative to first share his or her knowledge with and help others. Successful knowledge sharing (or interemployee helping) can then be achieved only after individuals have complete concentration of attention on the task of knowledge sharing (e.g., Csikszentmihalyi 1990), revealing a strong reason why flow experience is the critical mediator herein. As knowledge sharing and interemployee helping are both significantly influenced by flow experience as the only mediator, management should install a detection system that provides timely reports regarding the levels of flow experience among organizational members so that any potential negative impact on knowledge sharing may be avoided.

The significant relationship between work skills and flow experience reveals that online members' selection from current organizational employees should be done with caution. An organization recruiting employees who have insufficient work skills in, for example, interorganizational communication, resource-seeking, and dispute-solving, can ultimately ruin its own operation and activities. Even if the correct people are hired by an organization, they may still become unqualified later due to insufficient training and mentoring. Management should help strengthen members' skills periodically according to individuals' needs, and thus flow experience can be well maintained or increased to a substantial level.

The significant relationship between perceived control and flow experience found in this study shows that satisfying individuals' instinctual sense of control and autonomy is critical to enhancing their flow experience. Management should be able to find the right timing for empowerment and learn how to delegate members appropriately to conduct their work. Furthermore, the significant influence of perceived vividness on flow experience provides partial support for previous research that indicates job enrichment as a factor motivating employees (Maxwell 2008). Drab work is unlikely to motivate online members to work dynamically, decreasing their flow experience. Management can avoid losing the vividness of the job by encouraging members to try innovative ways to do their job.

\section{Future Research}

Given its theoretical focus on flow theory, this study has confined its consideration of the mediator to the only oneflow experience-suggested by theory. However, future researchers are advised to explore other potential mediators or individuals' personality characteristics (e.g., Maurer et al. 2008) beyond the scope of flow theory and compare their explanatory ability with that of the flow experience examined in this study. It should be noted that some of our measurement items (in the "Methods" section) were tailored to the specific context of online work modes and may require change in future studies if they are to be reapplied to holistically non-online working groups. Some factors that are seen more critical in non-online working contexts rather than in online contexts may be taken into consideration for future research (e.g., personal contacts related to gesture, voice, face-to-face interactions, or group dynamics).

Despite the positive nature of flow experience in general, excessive flow in work experience (e.g., turning focused employees into workaholics) might result in negative outcomes (e.g., burnout). This paradox between appropriate and excessive flow experience is worthy of intense exploration in future research. Another problematic issue in flow theory is the question of how employees learn which goals deserve attention and concentration. These issues cannot be arbitrarily concluded by this study because they lie outside of our research scope.

Acknowledgment This work was sponsored by the National Science Council of the Republic of China, Taiwan.

\section{Appendix: Measurement Items}

\section{Knowledge sharing (Source: Lin 2007b)}

KS1. I share my job experience with my online coworkers.

KS2. I share my expertise at the request of my online coworkers.

KS3. I share my ideas about jobs with my online coworkers.

KS4. I don't like to talk about my tips on jobs with my online co-workers. (Reverse coded) 
Interemployee helping (Source: Lin 2006)

IH1. I help others who have heavy work loads.

IH2. I help others who have been absent from work.

IH3. I willingly help others who have work-related problems.

IH4. I help orient new employees even though it is not required.

Flow experience (Source: Novak et al. 2000)

$\mathrm{TF} 1$. I experience immersion in online collaboration with my co-workers.

$\mathrm{TF} 2$. In general, I frequently pay close attention to online collaboration with co-workers.

TF3. I feel that I am deeply involved with online collaboration most of time.

Work skills (Source: Koufaris 2002)

SK1. I am very skilled at online collaboration with my co-workers.

SK2. I know how to find what I want (e.g., data or documents) through online collaboration.

SK3. I know more about performing online collaboration than others in different companies.

Self-fulfillment in challenges (Source: Koufaris 2002)

$\mathrm{CH} 1$. Practicing online collaboration with my co-workers challenges me to perform to the best of my ability.

$\mathrm{CH} 2$. Practicing online collaboration provides a good test of my skills.

CH3. Practicing online collaboration stretches my capabilities to the limits.

Perceived control (Source: Choi et al. 2007; Koufaris 2002)

CO1. I can interact easily with others through online collaboration.

$\mathrm{CO} 2$. I can easily contact my supervisor through online collaboration

CO3. Online collaboration gives me direct/timely feedback.

Perceived vividness (Source: Lin and Bhattacherjee 2008)

VI1. I feel dynamic having online collaboration with my co-workers.

VI2. Performing online collaboration with my co-workers provides me with a lot of vividness.

VI3. I enjoy online collaboration with my co-workers.

\section{References}

Ajzen, I. (1991). The theory of planned behavior. Organizational Behavior and Human Decision Processes, 50(2), 179-211.

Amabile, T. M., Hadley, C. N., \& Kramer, S. J. (2003). Creativity under the gun. Harvard Business Review, 80(8), 52-61.

Anderson, J. C., \& Gerbing, D. W. (1998). Structural equation modeling in practice: A review and recommended two-step approach. Psychological Bulletin, 103(3), 411-423.
Bakker, A. B. (2005). Flow among music teachers and their students: The crossover of peak experiences. Journal of Vocational Behavior, 66(1), 26-44.

Bandura, A. (1982). Self-efficacy mechanism in human agency. American Psychologist, 37(2), 122-147.

Bentler, P. M., \& Bonett, D. G. (1980). Significance tests and goodness-of-fit in the analysis of covariance structures. Psychological Bulletin, 88(3), 588-606.

Cabrera, A., \& Cabrera, E. F. (2002). Knowledge-sharing dilemmas. Organization Studies, 23(5), 687-710.

Carmeli, A. (2005). The relationship between organizational culture and withdrawal intentions and behavior. International Journal of Manpower, 26(2), 177-196.

Chan, T. S., \& Ahern, T. C. (1999). Targeting motivation-adapting flow theory to instructional design. Journal of Educational Computing Research, 21(2), 151-163.

Chen, K., Yen, D. C., Hung, S. Y., \& Huang, A. H. (2008). An exploratory study of the selection of communication media: The relationship between flow and communication outcomes. Decision Support Systems, 45(4), 822-832.

Choi, D. H., Kim, J., \& Kim, S. H. (2007). ERP training with a webbased electronic learning system: The flow theory perspective. International Journal of Human-Computer Studies, 65(3), 223-243.

Csikszentmihalyi, M. (1975). Beyond boredom and anxiety. San Francisco, CA: Jossey-Bass.

Csikszentmihalyi, M. (1990). Flow: The psychology of optimal experience. New York: Harpers Perennial.

Csikszentmihalyi, M. (1999). If we are so rich, what aren't we happy? American Psychologist, 54(10), 821-827.

Csikszentmihalyi, M., \& Rathunde, R. (1993). The measurement of flow in everyday life: Toward a theory of emergent motivation. Nebraska Symposium on Motivation, 40, 57-97.

Delespaul, P. A. E. G., Reis, H. T., \& deVries, M. W. (2004). Ecological and motivational determinants of activation: Studying compared to sports and watching TV. Social Indicators Research, 67(1/2), 129-143.

Easterby-Smith, M., Crossan, M., \& Nicolini, D. (2000). Organizational learning: debates past, present and future. Journal of Management Studies, 37(5), 783-796.

Easterby-Smith, M., \& Lyles, M. A. (2003). Introduction: Watersheds of organizational learning and knowledge management. In M. Easterby-Smith \& M. A. Lyles (Eds.), The Blackwell Handbook of Organizational Learning and Knowledge Management (pp. 1-15). Malden, MA: Oxford, Blackwell.

Eisenberger, R., Jones, J. R., Stinglhamber, F., Shanock, L., \& Randall, A. T. (2005). Flow experiences at work: For high need achievers alone? Journal of Organizational Behavior, 26(7), $755-775$

Erat, P., Desouza, K. C., Schäfer-Jugel, A., \& Kurzawa, M. (2006). Business customer communities and knowledge sharing: Exploratory study of critical issues. European Journal of Information Systems, 15(5), 511-524.

Fornell, C., \& Larcker, D. F. (1981). Evaluating structural equation models with unobservable variables and measurement error. Journal of Marketing Research, 18(1), 39-50.

Ghani, J. A. (1991). Flow in human-computer interactions: Test of a model. In J. Carey (Ed.), Human factors in information systems: Emerging theoretical bases. New Jersey: Ablex.

Ghani, J. A., \& Deshpande, S. P. (1994). Task characteristics and the experience of optimal flow in human-computer interaction. Journal of Psychology, 128(4), 381-389.

Guest, D. (2004). Flexible employment contracts, the psychological contract and employee outcomes: An analysis and review of the evidence. International Journal of Management Reviews, 5(1), $1-19$. 
Heckman, F. (1997). Designing organizations for flow experiences. Journal for Quality and Participation, 20(2), 24-33.

Hendriks, P. H. J. (1999). Why share knowledge? The influence of ICT on the motivation for knowledge sharing. Knowledge and Process Management, 6(2), 91-100.

Hoffman, D. L., \& Novak, T. P. (1996). Marketing in hypermedia computer-mediated environments: Conceptual foundations. Journal of Marketing, 60(3), 50-68.

Horwitz, F. M., Chang, T. H., Hesan, A. Q., Nonkwelo, C., Roditi, D., \& Van Eck, P. (2006). Human resource strategies for managing knowledge workers: An Afro-Asian comparative analysis. International Journal of Human Resource Management, 17(5), 775-811.

Horwitz, F. M., Heng, C. T., \& Quazi, H. A. (2003). Finders, keepers? Attracting, motivating and retaining knowledge workers. Human Resource Management Journal, 13(4), 23-44.

Hsu, S. H., Wen, M. H., \& Wu, M. C. (2009). Exploring user experiences as predictors of MMORPG addiction. Computers \& Education, 53(3), 990-999.

Hwang, Y. (2008). A preliminary examination of the factors for knowledge sharing in technology mediated learning. Journal of Information Systems Education, 19(4), 419-429.

Kiili, K., \& Lainema, T. (2008). Foundation for measuring engagement in educational games. Journal of Interactive Learning Research, 19(3), 469-488.

Koufaris, M. (2002). Applying the technology acceptance model and flow theory to online consumer behavior. Information Systems Research, 13(2), 205-223.

Lee, M. K. O., Cheung, C. M. K., Lim, K. H., \& Sia, C. L. (2006). Understanding customer knowledge sharing in web-based discussion boards: An exploratory study. Internet Research, 16(3), 289-303.

Liao, L. F. (2006). A flow theory perspective on learner motivation and behavior in distance education. Distance Education, 27(1), 45-62.

Lin, C. P. (2006). To help or not to help: Understanding the helping intentions from a mediating perspective of social network ties. Journal of Business Ethics, 63(2), 175-182.

Lin, H. F. (2007a). Knowledge sharing and firm innovation capability: An empirical study. International Journal of Manpower, 28(3/4), $315-332$.

Lin, C. P. (2007b). To share or not to share: Modeling tacit knowledge sharing, its mediators and antecedents. Journal of Business Ethics, 70(4), 411-428.

Lin, C. P., \& Bhattacherjee, A. (2008). Elucidating individual intention to use interactive information technologies: The role of network externalities. International Journal of Electronic Commerce, 13(1), 85-108.

Lin, C., \& Chang, S. (2008). A relational model of medical knowledge sharing and medical decision-making quality. International Journal of Technology Management, 43(4), 320-348.

Massimini, F., Csikszentmihaiyi, M., \& Carli, M. (1987). The monitoring of optimal experience: A tool for psychiatric rehabilitation. Journal of Nervous and Mental Disease, 175(9), $545-549$.

Mathwick, C., \& Rigdon, E. (2004). Play, flow, and the online search experience. Journal of Consumer Research, 31(2), 324-332.

Maurer, T. J., Lippstreu, M., \& Judge, T. A. (2008). Structural model of employee involvement in skill development activity: The role of individual differences. Journal of Vocational Behavior, 72(3), 336-350.

Maxwell, J. R. (2008). Work system design to improve the economic performance of the firm. Business Process Management Journal, 14(3), 432-446.

Mehrabian, A., \& Russel, J. A. (1974). An approach to environmental psychology. Cambridge, MA: MIT Press.

Mergel, I., Lazer, D., \& Binz-Scharf, M. C. (2008). Lending a helping hand: Voluntary engagement in knowledge sharing. International Journal of Learning and Change, 3(1), 5-22.

Mooradian, T., Renzl, B., \& Matzler, K. (2006). Who trusts? Personality, trust and knowledge sharing. Management Learning, 37(4), 523-540.

Novak, T. P., Hoffman, D. L., \& Yung, Y. F. (2000). Measuring the customer experience in online environments: A structural modeling approach. Marketing Science, 19(1), 22-44.

Organ, D. W. (1988). Organizational citizenship behavior: The good soldier syndrome. Lexington, MA: Lexington Books.

Pearce, J. M., \& Howard, S. (2004). Designing for flow in complex activity. In Proceedings of APCHI 2004 (pp. 349-358), Berlin.

Podsakoff, P. M., \& Organ, D. W. (1986). Self-reports in organizational research: Problems and prospects. Journal of Management, 12(4), 531-544.

Quinn, R. W. (2005). Flow in knowledge work: High performance experience in the design of national security technology. Administrative Science Quarterly, 50(4), 610-641.

Reynolds, N., Diamantopoulos, A., \& Schlegelmilch, B. B. (1993). Pretesting in questionnaire design: A review of the literature and suggestions for further research. Journal of the Market Research Society, 35(2), 171-182.

Rieber, L. P., Smith, L., \& Noah, D. (1998). The value of serious play. Educational Technology, 38(6), 29-37.

Rotter, J. B. (1996). Generalized expectancies for internal versus external control of reinforcement. Psychological monographs: general and application, 80 (1, Whole N. 609).

Schweinle, A., Meyer, D. K., \& Turner, J. C. (2006). Striking the right balance: Students' motivation and affect in elementary mathematics. Journal of Educational Research, 99(5), 271-293.

Siemsen, E., Balasubramanian, S., \& Roth, A. V. (2007). Incentives that induce task-related effort, helping, and knowledge sharing in workgroups. Management Science, 53(10), 1533-1550.

Spencer, D. G., \& Steers, R. M. (1980). The influence of personal factors and perceived work experiences on employee turnover and absenteeism. Academy of Management Journal, 23(3), 567-572.

Staples, D. S., \& Webster, J. (2008). Exploring the effects of trust, task interdependence and virtualness on knowledge sharing in teams. Information Systems Journal, 18(6), 617-640.

Wasko, M. M., \& Faraj, S. (2000). It is what one does: Why people participate and help others in electronic communities of practice. Journal of Strategic Information Systems, 9(2), 155-173.

Wasko, M. M., \& Faraj, S. (2005). Why should I share? Examining social capital and knowledge contribution in electronic networks of practices. MIS Quarterly, 29(1), 35-57.

Webster, J., Trevino, L. K., \& Ryan, L. (1993). The dimensionality and correlates of flow in human-computer interactions. Computers in Human Behavior, 9(4), 411-426.

Williams, R., \& Dargel, M. (2004). From servicescape to "cyberscape". Marketing Intelligence and Planning, 22(2/3), 310-320. 